\title{
The Effects of Credibility on Interest Rates in Turkey
}

\author{
M. Kadir DOĞAN ${ }^{*}$, Gülcan BOZDEMiR ${ }^{* *}$
}

\begin{abstract}
Credibility is crucial for managing inflation expectations in countries adopting inflation targeting. This study focuses on measurement of credibility and its relation with the interest rates. It aims to determine which measures of credibility best predict the variations of interest rates by using monthly data from Turkey in 2004-2012 period which adopted inflation targeting in 2002. Nine credibility indices are considered in the analysis. We find empirical evidence supporting the claim that higher credibility will lead to lower variations in interest rates of both monetary policy and the market. We also demonstrated that $\mathrm{Cl}_{C K}$ (proposed by Cecchetti and Krause, 2002) is the best credibility index in explaining the variations in both monetary policy interest rate and market interest rate.
\end{abstract}

Keywords: Credibility, Central Banking, Inflation Targeting, Inflation Expectations, Dynamic Inconsistency

JEL Code Classification: E42, E52, E58

\footnotetext{
*Assistant Professor, Ankara University, Faculty of Political Sciences, Department of Economics, Turkey. E-mail:doganmk@politics.ankara.edu.tr

"*enior Expert, Republic of Turkey Ministry of Economy, Turkey. E-mail: bozdemirg@ekonomi.gov.tr

Copyright $@$, 2014 International Ataturk Alatoo University.
} 


\section{Introduction}

Dynamic inconsistency problem in monetary policy arises if the policymakers are unable to commit to a policy rule. The dynamic inconsistency literature initiated by Kydland and Prescott (1977) and Barro and Gordon (1983) indicates that policymaking under commitment can lead to substantially better outcome than policymaking under discretion. This literature indicates that the absence of commitment in monetary policy is the main factor in the persistence of high inflation. Therefore, several countries began to adopt inflation targeting starting from early 1990s in order to reduce inflation and achieve price stability.

The main objective in the adoption of inflation targeting is to create an environment where inflation expectations converge to inflation target. Credibility of monetary authority is therefore crucial to manage the inflation expectations in inflation targeting regimes. Higher credibility will lead to lower disinflation costs.

The aim of this paper is to determine which measures of credibility best predict the variations of interest rates in Turkey. For this objective we used monthly data from Turkey between January 2004 and January 2012. Turkey adopted inflation targeting informally in 2002 and formally in 2006 in order to stabilize the price changes.

Nine credibility indices are evaluated in this paper as a measure of the credibility. $\mathrm{Cl}_{\mathrm{CK}}$ is proposed by Cecchetti and Krause (2002), $\mathrm{Cl}_{\mathrm{M}}$ is proposed by de Mendonça (2007), $\mathrm{Cl}_{\mathrm{A}}$ is introduced by de Mendonça and Souza (2009), $\mathrm{Cl}_{\mathrm{RC}}$ is introduced by Nahon and Meuer (2009). $\mathrm{Cl}_{\mathrm{CVE}}$ and $\mathrm{Cl}_{\mathrm{CVX}}$ are proposed in this paper. These indices measure the credibility by considering the deviation of the expected inflation from the inflation target. The last three credibility indices discussed in this paper $\left(\mathrm{Cl}_{\mathrm{AR}}\right.$, $\mathrm{Cl}_{\mathrm{WR}}, \mathrm{Cl}_{\mathrm{MAR}}$ ) are based on the reputation (past performance) of the monetary authority. The relationship between variation in interest rate and variation in credibility indices is analyzed. Two different interest rates are used in the analysis: monetary policy interest rate which is mainly determined by the central bank and market interest rate.

We provide empirical evidence supporting the claim that higher credibility will lead to lower variations in interest rates of both monetary policy and the market. We also show that $\mathrm{Cl}_{\mathrm{CK}}$ is the best credibility index in explaining the variations in both policy rate and market interest rate in Turkey.

The outline of the paper is as follows. Credibility measurement and credibility indices are discussed in section 2. Section 3 describes the data and application of the credibility indices for Turkey. Section 4 explains the empirical analysis and section 5 concludes.

\section{Credibility Measurement}

As central bank credibility has gained importance in the recent monetary policy literature, measuring the credibility becomes a significant issue. In practice since 
perception of credibility is a subjective and qualitative concept, it can be quantified through two different approaches: credibility creation and credibility impact approaches.

Credibility creation approach is a quantification of the determinants of credibility suggested in literature such as transparency, independence of central bank, accountability, history of honesty, past inflation performance, effectiveness in achievement of announced monetary policy targets, good governance, country risk and public debt. Mackiewicz-Lyziak (2009) calculates the credibility index for nine countries in the period between 1999 and 2007. This credibility index takes a value between 0 and 100, where 0 means no credibility and 100 means full credibility. It consists of seven sub-indices. Each sub-index is based one of the above-mentioned determinants of credibility. Index values were compiled for nine countries which are shown in Figure 1.

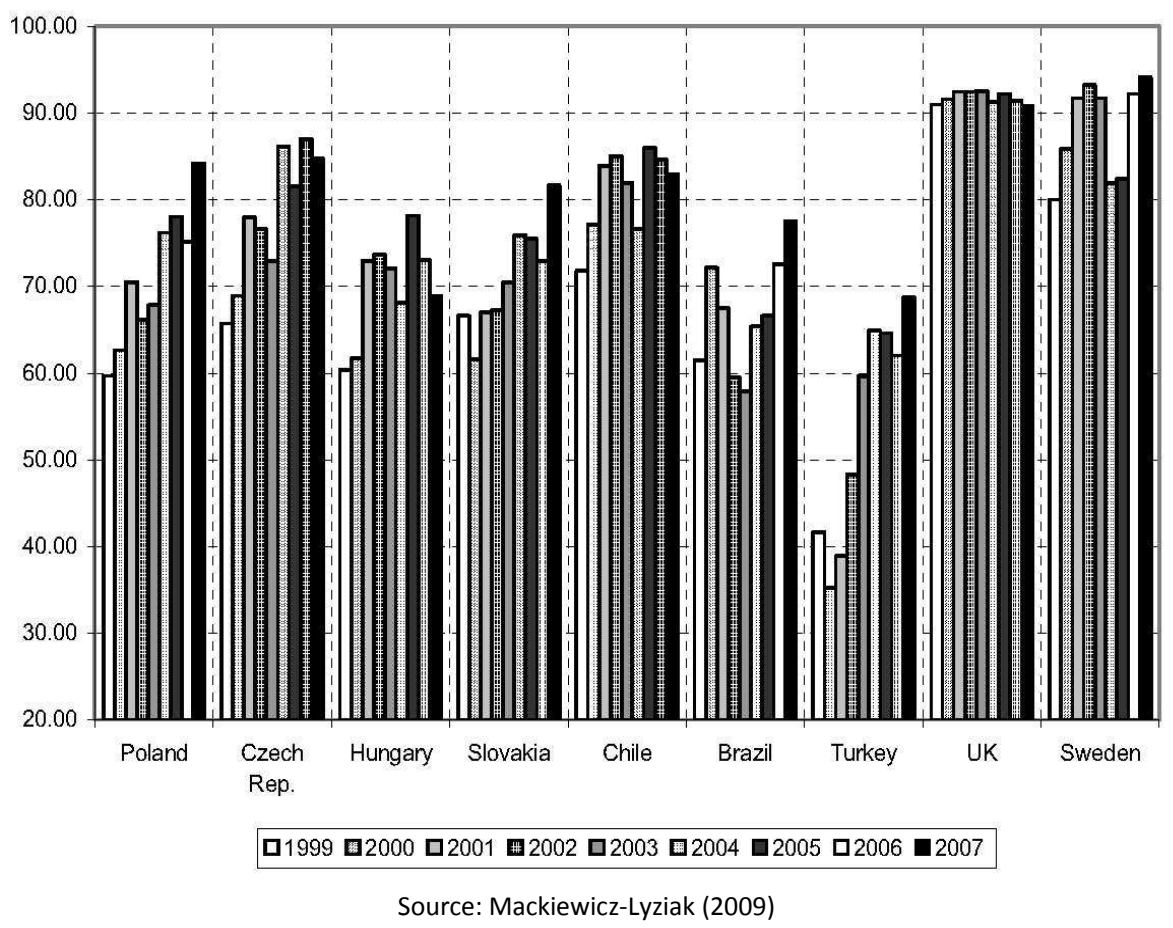

Figure 1. Index Values for Nine Countries

Credibility impact approach is a quantification of credibility effects based on inflation expectations of economic agents (Faust and Svensson, 2001). This measure can be quantified either with the deviations of inflation expectations from inflation target or the weight of inflation target in formation of inflation 
expectations. Inflation expectations may differ depending on the analyzed cohort of the agents.

Nahon and Meurer (2009) have used the credibility impact approach to measure the credibility of Brazilian Central Bank under inflation targeting program during the years 2000-2005. They used three indices formerly defined by Cecchetti and Krause (2002), Sicsu (2002), de Mendonça (2004) and proposed two more indices. de Mendonça and Souza (2009) have also measured the credibility of Brazilian Central Bank by using six credibility indices where three of them are based on the reputation of the central bank.

In this study, we mainly use the credibility impact approach to measure the credibility of the Central Bank of Turkey between 2004 and 2012. We describe the credibility indices used in the study in the next sub-section.

\subsection{Credibility Indices}

Following Agenor and Taylor (1993) and Svenson (2000) credibility changes inversely with the distance between inflation expectation $(E(\pi))$ and inflation target $(\pi)$. Thus the credibility indices based on credibility impact approach should represent this relation. Our first credibility index $\left(\mathrm{Cl}_{\mathrm{CK}}\right)$ is proposed by Cecchetti and Krause (2002). This credibility index takes the values between 0 and 1, assuming full credibility when it is equal to 1 .

$\mathrm{CI}_{\mathrm{CK}}= \begin{cases}1 & \text { if } \mathrm{E}(\pi) \leq \pi_{\mathrm{t}} \\ 1-\frac{1}{0.2-\pi_{\mathrm{t}}}\left[\mathrm{E}(\pi)-\pi_{\mathrm{t}}\right] & \text { if } \pi_{\mathrm{t}}<E(\pi)<0.2 \\ 0 & \text { if } \mathrm{E}(\pi) \geq 0.2\end{cases}$

The index is equal to 1 if the expected inflation is lower or equal to the inflation target. It decreases linearly while the expected inflation departs from the inflation target and gets the value of 0 if the expected inflation exceeds $20 \%$. In this index it is assumed that if the expected inflation exceeds \%20, then the central bank loses the control of inflation and thus has no credibility.

The second credibility index $\left(\mathrm{Cl}_{\mathrm{M}}\right)$ is proposed by de Mendonça (2007) which considers the tolerance limits together with the inflation target. It is computed by the following formula where $\pi^{\min }$ and $\pi^{\max }$ represent for the lower and upper bounds of inflation target respectively.

$\mathrm{CI}_{\mathrm{M}}= \begin{cases}1 & \text { if } \mathrm{E}(\pi)=\pi_{\mathrm{t}} \\ 1-\frac{1}{\pi_{\mathrm{t}}^{\text {max }}-\pi_{\mathrm{t}}}\left|\mathrm{E}(\pi)-\pi_{\mathrm{t}}\right| & \text { if } \pi_{\mathrm{t}}^{\min } \leq \mathrm{E}(\pi) \leq \pi_{\mathrm{t}}^{\max } \\ 0 & \text { if } \mathrm{E}(\pi)>\pi_{\mathrm{t}}^{\max } \text { or } \mathrm{E}(\pi)<\pi_{\mathrm{t}}^{\min }\end{cases}$ 
This index equals to 1 if the expected inflation is equal to inflation target and equals to 0 if the expected inflation is either lower than the lower bound inflation target or greater than the upper bound inflation target. If the expected inflation is in tolerance interval, it decreases linearly while the expected inflation differs from the inflation target.

The third credibility index $\left(\mathrm{Cl}_{A}\right)$ is proposed by de Mendonça and Souza (2009) which assumes that the central bank has full credibility while the expected inflation is in tolerance interval.

$$
\mathrm{CI}_{\mathrm{A}}= \begin{cases}1 & \text { if } \pi_{\mathrm{t}}^{\min } \leq \mathrm{E}(\pi) \leq \pi_{\mathrm{t}}^{\max } \\ 1-\frac{1}{0.2-\pi_{\mathrm{t}}^{\max }}\left[\mathrm{E}(\pi)-\pi_{\mathrm{t}}^{\max }\right] & \text { if } \pi_{\mathrm{t}}^{\max }<E(\pi)<0.2 \\ 1-\frac{1}{-\pi_{\mathrm{t}}^{\min }}\left[\mathrm{E}(\pi)-\pi_{\mathrm{t}}^{\min }\right] & \text { if } 0<E(\pi)<\pi_{\mathrm{t}}^{\min } \\ 0 & \text { if } \mathrm{E}(\pi) \geq 0.2 \text { or } \mathrm{E}(\pi) \leq 0\end{cases}
$$

$\mathrm{Cl}_{\mathrm{A}}$ takes the value of 1 if the expected inflation is in tolerance interval. It takes the value of zero if the expected inflation is either greater than $20 \%$ or less than zero. Otherwise, it decreases linearly while expected inflation departs from tolerance interval and takes a value in the $(0,1)$ interval.

The forth credibility index (CIRC) is suggested by Nahon and Meuer (2009) which assumes that the central bank has full credibility while the expected inflation is lower than the upper bound of inflation target.

$\mathrm{CI}_{\mathrm{RC}}= \begin{cases}\frac{\pi_{\mathrm{t}}^{\max }}{\mathrm{E}(\pi)} & \text { if } \mathrm{E}(\pi)>\pi_{\mathrm{t}}^{\max } \\ 1 & \text { if } \mathrm{E}(\pi) \leq \pi_{\mathrm{t}}^{\max }\end{cases}$

$\mathrm{Cl}_{\mathrm{RC}}$ is equal to 1 if the expected inflation is less than upper bound of the inflation target and decreases while expected inflation departs from the upper bound of the inflation target and takes value in the $(0,1)$ interval. It converges to zero while the expected inflation goes to infinite.

We propose two more credibility indices $\left(\mathrm{Cl}_{\mathrm{CVE}}\right.$ and $\left.\mathrm{Cl}_{\mathrm{CVX}}\right)$ in this paper. Similar to $\mathrm{Cl}_{\mathrm{M}}$, these indices take the value of 1 if the expected inflation is equal to the target inflation and take the value of 0 if the expected inflation is outside of tolerance interval. In the tolerance interval, $\mathrm{Cl}_{\mathrm{CVE}}$ decreases at an increasing rate and $\mathrm{Cl}_{\mathrm{CVX}}$ decreases at a decreasing rate while the expected inflation differs from the inflation target. Thus the slope of $\mathrm{Cl}_{\mathrm{CVE}}$ decreases and the slope of $\mathrm{Cl}_{\mathrm{CVX}}$ increases in the tolerance interval. In other words, $\mathrm{Cl}_{\mathrm{CVE}}$ has a concave shape and $\mathrm{Cl}_{\mathrm{CVX}}$ has a convex shape. 


$$
\begin{aligned}
& \mathrm{CI}_{\mathrm{CVE}}= \begin{cases}1-\left[\frac{\mathrm{E}(\pi)-\pi_{\mathrm{t}}}{\pi_{\mathrm{t}}^{\max }-\pi_{\mathrm{t}}}\right]^{2} & \text { if } \pi_{\mathrm{t}}^{\min } \leq \mathrm{E}(\pi) \leq \pi_{\mathrm{t}}^{\max } \\
0 & \text { otherwise }\end{cases} \\
& \mathrm{CI}_{\mathrm{CVX}}= \begin{cases}1-\sqrt{\frac{\mathrm{E}(\pi)-\pi_{\mathrm{t}}}{\pi_{\mathrm{t}}^{\max }-\pi_{\mathrm{t}}}} & \text { if } \pi_{\mathrm{t}}^{\min } \leq \mathrm{E}(\pi) \leq \pi_{\mathrm{t}}^{\max } \\
0 & \text { otherwise }\end{cases}
\end{aligned}
$$

In case of a deviation of expected inflation from inflation target, $\mathrm{Cl}_{\mathrm{cvx}}$ will cause a higher credibility loss than $\mathrm{Cl}_{M}$, whereas $\mathrm{Cl}_{\mathrm{CVE}}$ will cause a lower credibility loss than $\mathrm{Cl}_{\mathrm{M}}$.

Credibility creation approach considers the deviation of the expected inflation from the inflation target. de Mendonça (2007) pointed out that credibility is synonymous with reputation in economies where credibility is still being built. Consequently, de Mendonça and Souza (2009) proposed an alternative method for measuring credibility by using the reputation instead of expectations. Note that reputation is earned due to the past performance of the central bank whereas credibility is gained based on agents' expectations. However, past performance of the central bank can be effective in the formation of expectations and thus reputation can be used in measuring the credibility. In order to build credibility indices based on reputation, we use the reputation index (R) proposed by de Mendonça and Souza (2009).

$$
\mathrm{R}= \begin{cases}1 & \text { if } \pi_{\mathrm{t}}^{\min } \leq \pi^{\mathrm{OBS}} \leq \pi_{\mathrm{t}}^{\max } \\ 1-\frac{1}{0.2-\pi_{\mathrm{t}}^{\max }}\left[\pi^{\mathrm{OBS}}-\pi_{\mathrm{t}}^{\mathrm{max}}\right] & \text { if } \pi_{\mathrm{t}}^{\max }<\pi^{\mathrm{OBS}}<0.2 \\ 1-\frac{1}{-\pi_{\mathrm{t}}^{\min }}\left[\mathrm{E}(\pi)-\pi_{\mathrm{t}}^{\min }\right] & \text { if } 0<\pi^{\mathrm{OBS}}<\pi_{\mathrm{t}}^{\min } \\ 0 & \text { if } \pi^{\mathrm{OBS}} \geq 0.2 \text { or } \pi^{\mathrm{OBS}} \leq 0\end{cases}
$$

The reputation index is similar to $\mathrm{Cl}_{\mathrm{A}}$ where expected inflation is replaced with observed inflation $\left(\pi^{O B S}\right)$. Reputation index takes the value of 1 if the observed inflation is in the tolerance interval and takes the value of 0 if the observed inflation is less than zero or higher than $20 \%$. Otherwise it is in $(0,1)$ interval and decreases linearly while the observed inflation departs from tolerance limits.

Based on the reputation index three credibility indices $\left(\mathrm{Cl}_{\mathrm{AR}}, \mathrm{Cl}_{\mathrm{WR}}, \mathrm{Cl}_{\mathrm{MAR}}\right)$ are established as follows.

$C I_{A R}^{t}=\frac{\sum_{i=1}^{t} R^{i-1}}{t} ; \quad C I_{W R}^{t}=\frac{\sum_{i=1}^{t} i \cdot R^{i-1}}{\sum_{i=1}^{t} i} ; \quad C I_{M A R}^{t}=\frac{\sum_{i=t-12}^{t-1} R^{i}}{12}$ 
$\mathrm{Cl}_{A R}^{t}$ is the average reputation at time $t\left(\mathrm{R}^{0}\right.$ is equal to initial reputation). $\mathrm{Cl}_{W R}^{t}$ is the weighted average reputation at time $t$ where the given weight increases while the time approaches to the current period. So $\mathrm{Cl}_{\mathrm{WR}}^{\mathrm{t}}$ gives more weights to the reputation of recent periods. $\mathrm{Cl}_{\text {MAR }}^{t}$ is the moving average reputation at time $t$ where the lag is chosen as 12 . It is simply the average of the reputations of the last twelve periods.

The first six credibility indices and the reputation index are illustrated in Figure 2.

\section{Credibility Measurement in Turkey}

\subsection{Data and Assumptions}

The data used in the analysis were taken from Under secretariat of Treasury, Central Bank of Republic of Turkey (CBRT) and Istanbul Stock Exchange Markets. The data are in monthly frequencies and belong to the period between January 2004 and January 2012.

Expected inflation has taken from CBRT public surveys comprehending both financial sector and households answers. Even though the data of expected inflation are available for years 2001-2003, the results of CBRT public surveys to determine the expected inflation are not very efficient for this period (Kara and Küçük-Tuğer, 2010). We therefore do not use the data for years 2001-2003 in the analysis.

Inflation targets and observed inflation rates for the years 2003-2011 are given in Table 1. As inflation targets are decided annually, we transform the end year targets to monthly frequency by using linear interpolation method highlighted in the part "inflation path descriptions consistent with the end-year target and the uncertainty band" under CBRT's monetary policy papers.

Table 1. Inflation Targets and Observed Inflation Rates

\begin{tabular}{ccc}
\hline Year & Inflation Target (\%) & Observed Inf. (\%) \\
\hline 2003 & 20 & 18.4 \\
2004 & 12 & 9.3 \\
2005 & 8 & 7.7 \\
2006 & 5 & 9.7 \\
2007 & 4 & 8.4 \\
2008 & 4 & 10.1 \\
2009 & 7.5 & 6.5 \\
2010 & 6.5 & 6.4 \\
2011 & 5.5 & 10.4 \\
\hline
\end{tabular}


M. Kadir DOGAN \& Gulcan BOZDEMIR

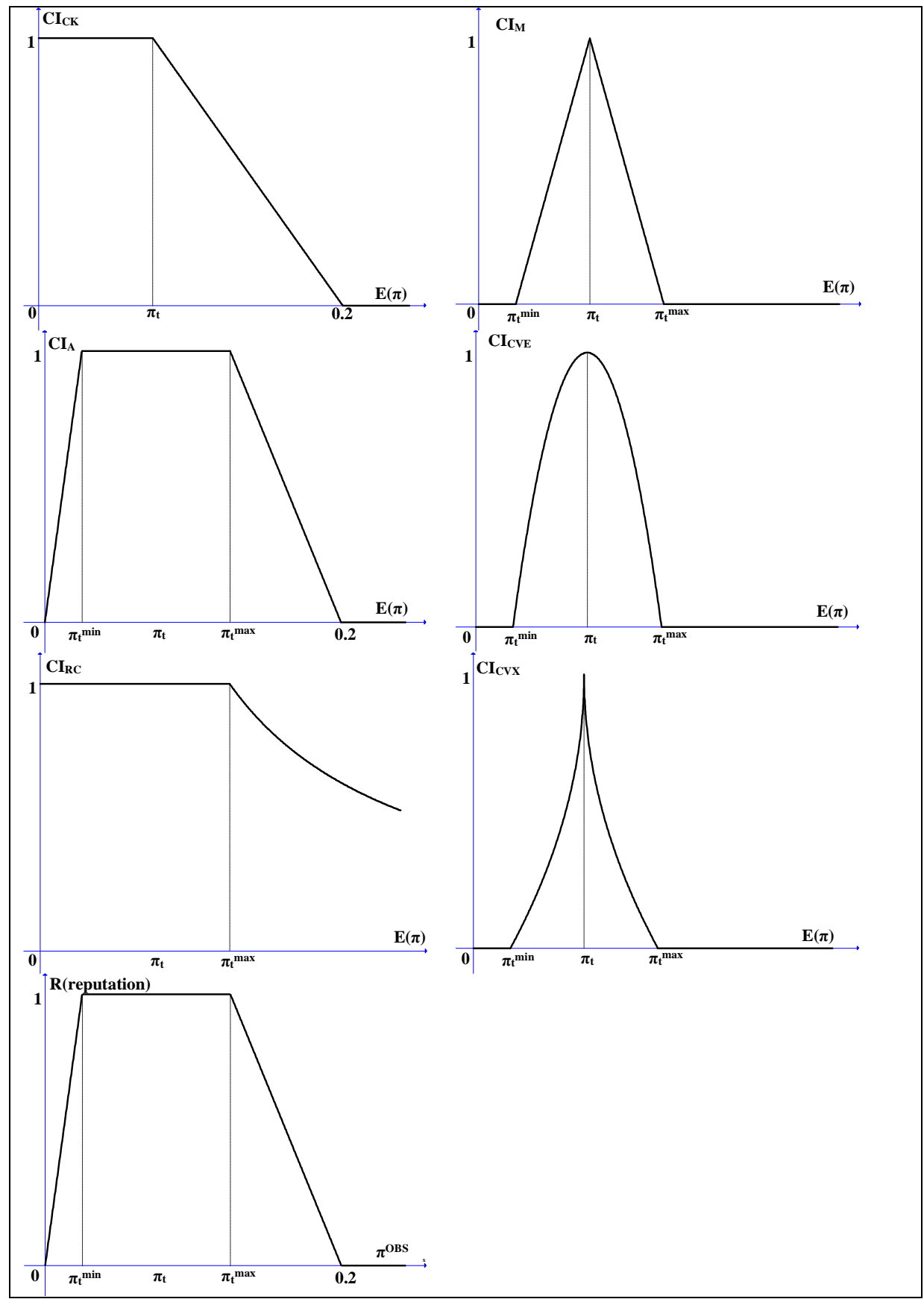

Figure 2: Illustration of Credibility Indices and Reputation Index

Page $\mid 78$

EJBE 2014, 7 (14) 
Those policy papers have been prepared in advance at the beginning of each year and shared with public for the years 2002-2011. ${ }^{1}$ As there was an implicit implementation of inflation targeting program before 2006, those monetary and exchange rate policy papers didn't include inflation paths before that time. Thus, we have assumed that CBRT's policy preference to decrease the inflation to the target levels would be the same before 2006. Moreover, there is no monetary explanation of inflation paths shared with public for 2010 and 2011 as the difference between the inflation targets for those years are small to describe. It is assumed that monetary paths were not parallel with the seasonal price changes generally observed in Turkish economy. However, as CBRT would declare to follow a linear decreasing path for the belonging years we thought that it is meaningful to follow this path for the years in concern. There may be some critics to CBRT's approach. But, a smooth declining path towards the announced target is also an accepted way in inflation targeting literature. Inflation target, expected inflation, observed inflation and the tolerance interval between January 2004 and January 2012 is given in Figure 3.

As it can be seen in Figure 3, expected inflation is usually higher than inflation target in Turkey (exceptions: March-April 2004, March 2005, February-November 2009). On the other hand, expected inflation is usually in the tolerance interval (exceptions: June 2006-September 2007, Dec 2007-January 2008, March-May 2008 and December 2011). Observed inflation is higher than the upper bound of the tolerance interval in July 2005, September 2005-January 2009, February-June 2010, August-October 2010 and October 2011-January 2012.

For the policy rate we have used overnight CBRT's interest rate which is also published according to the annually cumulated monthly data. Overnight interest rate was used as policy rate until November 2010 by CBRT. However, they began to use weekly REPO interest rates since December 2010. Thus, we have also included this change in our data set.

For the market interest rate, we have used the average interest rate of the indicator treasury bond that was exchanged mostly in each day by transforming those daily frequencies into annually cumulated monthly averages.

Moreover, since the CBRT accepted the inflation target regime formally in 2006 (there was an implicit inflation targeting regime between the years 2002-2006), CBRT did not explicitly accept an interval for inflation target before 2006 which is necessary to calculate most of the indices. Beginning from the year 2006, as CBRT accepted the inflation target regime formally, we have chosen the declared tolerance limits for the target as $(-2,+2)$. We have also used the same tolerance limits for the years 2004-2005.

\footnotetext{
${ }^{1}$ General Framework of Inflation Targeting and Monetary and Exchange Rate Policy for 2002-2011 can be reached at http://www.tcmb.gov.tr/yeni/eng/. Last accessed at 04/10/2012.
} 


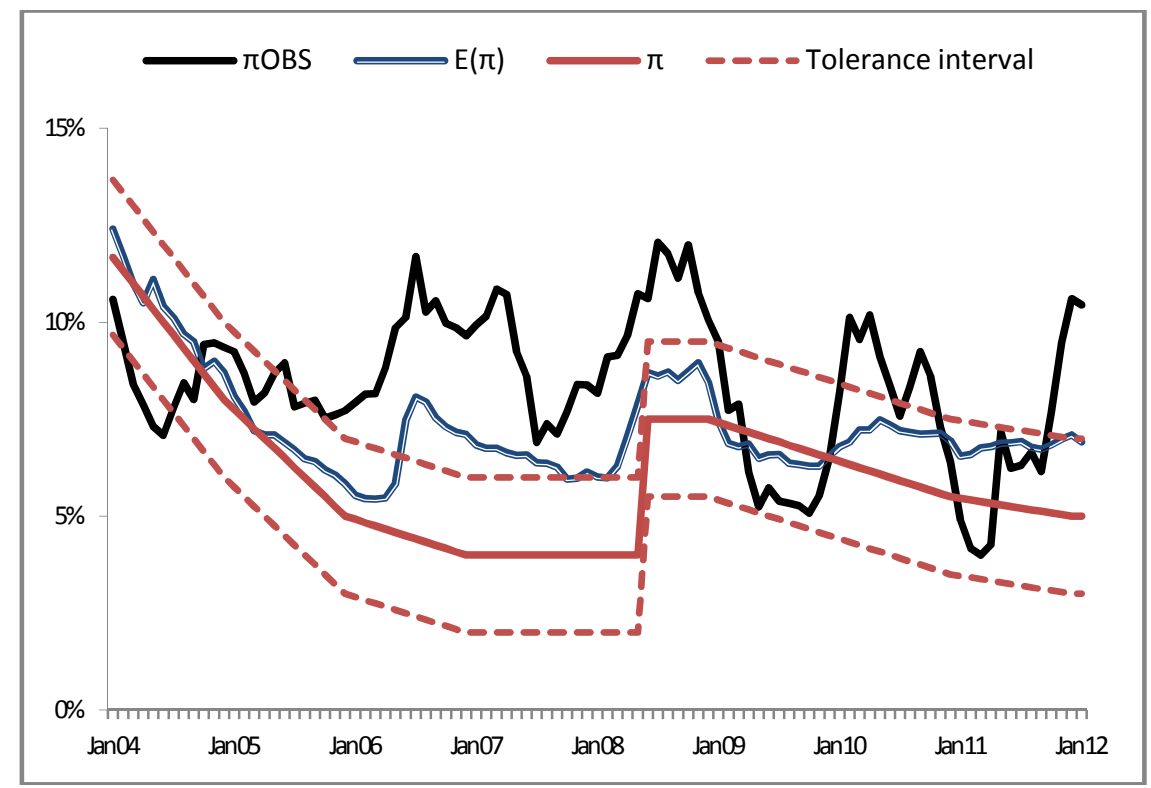

Figure 3. Inflation Target, Expected Inflation, Observed Inflation and the Tolerance Interval

It is also important to mention that CBRT has revised the inflation targets in June 2008 (see Figure 3). Before the revision inflation targets were 4\% for both 2009 and 2010. In June 2008 the inflation target was updated as $7.5 \%$ for 2009 and $6.5 \%$ for 2010. Thus, we have employed the updated inflation targets beginning from June 2008. We should also note that we omitted the data for the June 2008 from the analysis.

\subsection{Application of Credibility Indices for Turkey}

The credibility indices are computed for Turkey between January 2004 and January 2012. The paths of credibility indices are given in Figure $4 . \mathrm{Cl}_{\mathrm{CK}}$ takes values in $[0.758,1]$ interval with an average of 0.914. It reaches to its minimum in May 2008.

The paths of $\mathrm{Cl}_{A}$ and $\mathrm{Cl}_{\mathrm{RC}}$ are similar since the expected inflation is never less than the lower bound of the inflation target. The values of $\mathrm{Cl}_{A}$ are in $[0.866,1]$ interval with an average of 0.987 and the values of $\mathrm{Cl}_{\mathrm{RC}}$ are in $[0.761,1]$ interval with an average of 0.975 . Both indices get their minimum values in May 2008. 
The Effects of Credibility on Interest Rates in Turkey
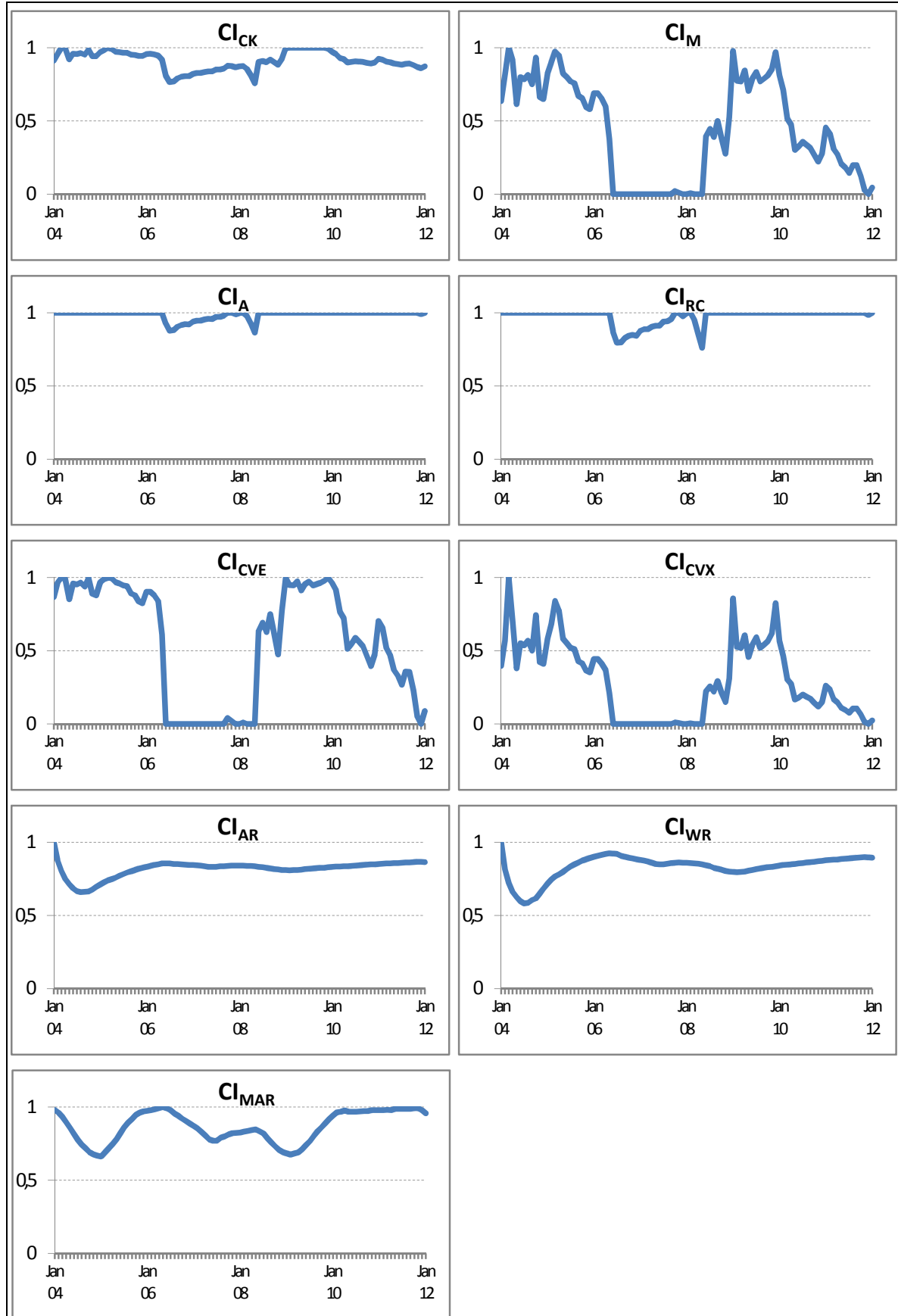

Figure 4. The Paths of Credibility Indices in Turkey

EJBE 2014, 7 (14)

Page | 81 
$\mathrm{Cl}_{\mathrm{CVE}}, \mathrm{Cl}_{\mathrm{M}}$, and $\mathrm{Cl}_{\mathrm{CVX}}$ takes values in $[0,1]$ interval with averages of $0.563,0.433$ and 0.293 respectively. They are equal to zero when the expected inflation is outside the tolerance limits by their settings. Thus they are equal to zero in June 2006September 2007, December 2007-January 2008, March-May 2008 and December 2011. These indices differ from each other due to different losses in credibility when the expected inflation is in tolerance interval but deviates from the target. In case of a deviation from inflation target, the credibility loss in $\mathrm{Cl}_{\mathrm{CVE}}$ will be lower compared to $\mathrm{Cl}_{M}$ and the credibility loss in $\mathrm{Cl}_{M}$ will be lower compared to $\mathrm{Cl}_{\mathrm{CVx}}$. Thus, the graph of $\mathrm{Cl}_{\mathrm{Cvx}}$ path is below the graph of $\mathrm{Cl}_{\mathrm{M}}$ path and the latter is below the graph of $\mathrm{Cl}_{\mathrm{CVE}}$ path.

The difference among the credibility indices based on reputation $\left(\mathrm{Cl}_{\mathrm{AR}}, \mathrm{Cl}_{\mathrm{WR}}\right.$ and $\left(\mathrm{Cl}_{\mathrm{MAR}}\right)$ is the weight given to the reputation in the previous periods. $\mathrm{Cl}_{\mathrm{AR}}$ gives equals weights to previous reputations while $\mathrm{Cl}_{W R}$ gives more weights to recent reputations. Thus, even though they have similar paths, the path of $\mathrm{Cl}_{A R}$ is smoother than the path of $\mathrm{Cl}_{\mathrm{WR}}$. The average of $\mathrm{Cl}_{\mathrm{AR}}$ is equal to 0.821 and a bit lower than the average of $\mathrm{Cl}_{\mathrm{WR}}$ which is equal to 0.835 . Both indices take their minimum values in July 2004 (0.660 for $\mathrm{Cl}_{\mathrm{AR}}$ and 0.581 for $\left.\mathrm{Cl}_{\mathrm{WR}}\right)^{2}{ }^{2}$

The path of $\mathrm{Cl}_{\mathrm{MAR}}$ exhibits more variations compared to the paths of $\mathrm{Cl}_{\mathrm{AR}}$ and $\mathrm{Cl}_{\mathrm{WR}}$ since it only considers the reputations in the last year (the last twelve periods). The average of $\mathrm{Cl}_{\text {MAR }}$ is equal to 0.867 , which takes the minimum value $(0.663)$ in January 2005 and the maximum value (1.000) in May 2006.

\section{Empirical Analysis}

As the credibility of the central bank increases, its ability to affect the public expectation is also increases. Thus, it is expected that change in the interest rates will be inversely related to the credibility of the central bank. We analyze the relation between credibility indices and the interest rate. Two different interest rates are used in the analysis. First one is the policy rate which is mainly determined by the central bank and the second one is market interest rate which is the average interest rate of the indicator treasury bond.

In the first step of empirical analysis, unit root tests have been carried out for all of the variables. Augmented Dickey-Fuller (ADF), Philips-Perron(PP), Dickey-Fuller GLS (DF-GLS) and Kwiatkowski-Phillips-Schmidt-Shin (KPSS) tests are held and the results are shown in Table 2.

According to ADF and PP tests, all the series are non-stationary at level but stationary at first differences at \%1 significance level. However, $\mathrm{Cl}_{\mathrm{A}}$ and $\mathrm{Cl}_{\mathrm{RC}}$ series

\footnotetext{
${ }^{2}$ Note that the observed inflation in December 2003 is in the tolerance interval, so the reputation index takes the value of 1 for that month. The values of $\mathrm{Cl}_{\mathrm{AR}}$ and $\mathrm{Cl}_{\mathrm{WR}}$ are therefore equal to 1 in the first period of analysis (January 2004). The average of reputation index between January 2003 and December 2003 is equal to 0.981 and thus $\mathrm{Cl}_{\text {MAR }}$ takes that value in the first period.
} 
are stationary at level according to these tests at $\% 5$ significance level. On the other hand, KPPS test confirms that $\mathrm{Cl}_{\mathrm{A}}$ and $\mathrm{Cl}_{\mathrm{RC}}$ series are not stationary at level at $\% 5$ significance level. ${ }^{3}$ We treated all the series in the analysis as I(1).

If the credibility indices cause changes in interest rates, then we will observe that changes in credibility indices will precede changes in interest rates.

\section{Table 2. Unit Root Test Results}

\begin{tabular}{lcccccccc}
\hline Series & \multicolumn{2}{c}{ ADF } & \multicolumn{2}{c}{ PP } & \multicolumn{2}{c}{ DF-GLS } & \multicolumn{2}{c}{ KPSS } \\
\hline & Level & First Dif. & Level & First Dif. & Level & First Dif. & Level & First Dif. \\
\cline { 2 - 8 }$(\mathrm{E}(\pi)-\pi)$ & -1.907 & $-6.310^{(* *)}$ & -2.003 & $-6.188^{(* *)}$ & -1.934 & $-5.652^{(* *)}$ & $0.150^{(*)}$ & 0.043 \\
$\mathrm{Cl}_{\mathrm{CK}}$ & -2.098 & $-7.286^{(* *)}$ & -2.16 & $-7.161^{(* *)}$ & -2.155 & $-5.537^{(* *)}$ & $0.147^{(*)}$ & 0.044 \\
$\mathrm{Cl}_{\mathrm{M}}$ & -1.568 & $-9.255^{(* *)}$ & -1.646 & $-9.306^{(* *)}$ & -1.793 & $-7.345^{(* *)}$ & $0.158^{(*)}$ & 0.08 \\
$\mathrm{Cl}_{\mathrm{A}}$ & $-3.252^{(*)}$ & $-5.280^{(* *)}$ & $-3.210^{(*)}$ & $-3.339^{(*)}$ & $-3.219^{(*)}$ & $-5.057^{(* *)}$ & $0.169^{(*)}$ & 0.048 \\
$\mathrm{Cl}_{\mathrm{RC}}$ & $-3.071^{(*)}$ & $-5.124^{(* *)}$ & $-3.048^{(*)}$ & $-4.192^{(* *)}$ & -3.035 & $-4.988^{(* *)}$ & $0.176^{(*)}$ & 0.044 \\
$\mathrm{Cl}_{\mathrm{CVE}}$ & -1.774 & $-7.876^{(* *)}$ & -1.49 & $-7.766^{(* *)}$ & -1.828 & $-7.127^{(* *)}$ & $0.161^{(*)}$ & 0.074 \\
$\mathrm{Cl}_{\mathrm{CVX}}$ & -2.347 & $-10.649^{(* *)}$ & -2.116 & $-11.882^{(* *)}$ & -2.63 & $-7.127^{(* *)}$ & $0.159^{(*)}$ & 0.084 \\
$\mathrm{Cl}_{\mathrm{AR}}$ & -0.916 & $-9.517^{(* *)}$ & -1.231 & $-9.517^{(* *)}$ & -0.012 & -0.975 & $0.165^{(*)}$ & 0.144 \\
$\mathrm{Cl}_{\mathrm{WR}}$ & -1.01 & $-9.459^{(* *)}$ & -1.483 & $-9.452^{(* *)}$ & -0.315 & -0.963 & $0.166^{(*)}$ & 0.134 \\
$\mathrm{Cl}_{\mathrm{MAR}}$ & -1.09 & $-9.315^{(* *)}$ & -1.476 & $-9.314^{(* *)}$ & -0.807 & $-9.300^{(* *)}$ & 0.072 & 0.134 \\
$\mathrm{i}_{\mathrm{CB}}$ & -1.261 & $-5.875^{(* *)}$ & -1.939 & $-5.838^{(* *)}$ & -1.725 & $-3.815^{(* *)}$ & 0.127 & 0.122 \\
$\mathrm{i}_{\mathrm{MAR}}$ & -1.579 & $-7.385^{(* *)}$ & -1.704 & $-7.281^{(* *)}$ & -2.167 & $-7.585^{(* *)}$ & 0.099 & 0.098 \\
\hline
\end{tabular}

Statistical significance: ${ }^{(*)}$ at $\% 1$ level, ${ }^{(*)}$ at $\% 5$ level.

To formally analyze the precedence in the movements of credibility indices and interest rates, pair wise Granger causality tests were conducted (see the results in Table 3). Test results shows that $\mathrm{D}\left(\mathrm{Cl}_{\mathrm{CK}}\right), \mathrm{D}\left(\mathrm{Cl}_{\mathrm{M}}\right), \mathrm{D}\left(\mathrm{Cl}_{\mathrm{CVE}}\right)$ and $\mathrm{D}\left(\mathrm{Cl}_{\mathrm{WR}}\right)$ Granger causes $D\left(i_{\text {MAR }}\right)$ at \%1 significance level and $D(E(\pi)-\pi)$ Granger causes $D\left(i_{\text {MAR }}\right)$ at \%5 significance level. On the other hand, the unique credible index whose movements precede the variations in the policy rate is $\mathrm{Cl}_{\mathrm{CVE}}$ which is first proposed in this paper. $\mathrm{D}\left(\mathrm{Cl}_{\mathrm{CVE}}\right)$ Granger causes $\mathrm{D}\left(\mathrm{i}_{\mathrm{CB}}\right)$ at \%1 significance level.

There is also some evidence of causality from variation in interest rate to changes in credibility for both market and monetary policy interest rates. $D\left(i_{\text {MAR }}\right)$ Granger causes to $\mathrm{D}\left(\mathrm{Cl}_{\mathrm{CK}}\right), \mathrm{D}\left(\mathrm{CI_{M }}\right), \mathrm{D}\left(\mathrm{Cl} \mathrm{CVx}_{\mathrm{Cr}}\right)$ at \%5 significance level. $\mathrm{D}\left(\mathrm{i}_{\mathrm{CB}}\right)$ Granger causes to $D(E(\pi)-\pi), D\left(C I_{C K}\right), D\left(C I_{M}\right), D\left(C I_{C V X}\right)$ at \%1 significance level.

These results show that changes in monetary policy and the market interest rates precede the variations in the credibility. We performed pairwise Granger causality tests to examine the precedence in the variations market interest rate and policy rate (see Table 4 for the results). It shows that there is bicausality between them.

\footnotetext{
${ }^{3}$ Other contradictions to ADF and PP test results are that DF-GLS test cannot reject the non-stationarity of the first differences $\mathrm{Cl}_{A R}$ and $\mathrm{Cl}_{\text {WR }}$ series at \%5 level and KPPS test cannot reject the stationarity of $\mathrm{Cl}_{\mathrm{MAR}}, \mathrm{i}_{\mathrm{CB}}$ and $\mathrm{i}_{\mathrm{MAR}}$ series at \%5 level.
} 
Table 3. Granger Causality Test Results

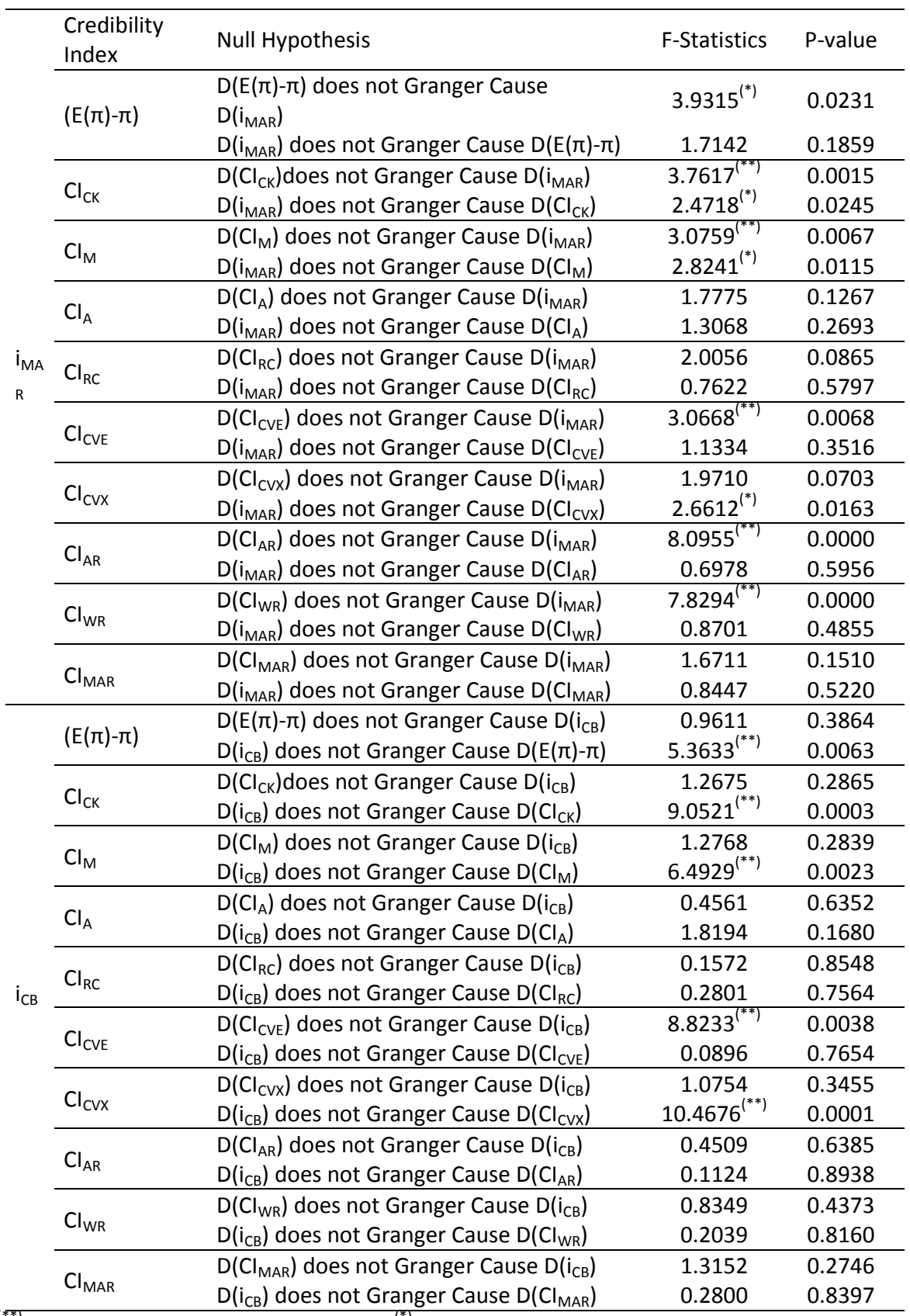

${ }^{(*)}$ indicates significance at \%1 level and ${ }^{(*)}$ indicates significance at \%5 level. 
Table 4. Granger Causality Test Results for the Interest Rates

\begin{tabular}{ccc}
\hline Null Hypothesis & F-Statistics & P-value \\
\hline $\mathrm{D}\left(\mathrm{i}_{\text {MAR }}\right)$ does not Granger Cause $\mathrm{D}\left(\mathrm{i}_{\mathrm{CB}}\right)$ & $3.8069^{* *}$ & 0.0129 \\
$\mathrm{D}\left(\mathrm{i}_{\mathrm{CB}}\right)$ does not Granger Cause $\mathrm{D}\left(\mathrm{i}_{\text {MAR }}\right)$ & $3.1078^{(*)}$ & 0.0306 \\
\hline$\left.*^{*}\right)$
\end{tabular}

${ }^{(*)}$ indicates significance at \%5 level.

We also analyze the empirical relation between credibility indices and the market interest rate and the empirical relation between credibility indices and the policy rate. In general we make multiple regressions on the following models as proposed in de Mendonça and Souza (2009).

$\Delta I R_{C B}^{t}=\beta_{0 i}+\beta_{1 i} \Delta\left[E^{t-1}(\pi)-\pi_{t-1}\right]+\beta_{2 i} \Delta C_{i}^{t}+\varepsilon_{i}$

$\Delta I R_{M A R}^{t}=\beta_{0 i}+\beta_{1 i} \Delta I R_{M A R}^{t-1}+\beta_{2 i} \Delta C_{i}^{t}+\varepsilon_{i}$

The first model (eq. 1) expresses the variations in policy rate by using the changes in credibility indices. The difference between expected inflation and target inflation in the previous period is used as control variable in the model. If the variations in policy rate would decrease while credibility is increasing, then an increase in a credibility index should reduce the variations in policy rate. We therefore expect negative and statistical significance coefficients for credibility indices in the estimation of the first model.

For each credibility index we choose the appropriate model by using Akaike and Schwarz information criteria. ${ }^{4}$ Estimation results for the variations in policy rate are given in Table $5 .^{5}$ In the estimation of the variation in policy rate, two models (for $\mathrm{Cl}_{\mathrm{AR}}$ and $\mathrm{Cl}_{\mathrm{WR}}$ ) are significant at \%5 level and the rest of the models are significant at $\% 1$ level.

By comparing the models in terms of adjusted $\mathrm{R}^{2}$, we see that the best credibility index is $\mathrm{Cl}_{\mathrm{CK}}$ which accounts for the $39.11 \%$ of the variation in $\mathrm{D}\left(\mathrm{i}_{\mathrm{CB}}\right)$. The control variable (lag of difference between expected inflation and inflation target) accounts for only \%7.12 of the variation in $\mathrm{D}\left(\mathrm{i}_{\mathrm{CB}}\right)$. Following $\mathrm{Cl}_{\mathrm{CK}}$, the highest adjusted $\mathrm{R}^{2}$ values are as follows. $\mathrm{Cl}_{\mathrm{CVE}}: 34.81 \%, \mathrm{Cl}_{\mathrm{A}}: 30.71 \%, \mathrm{Cl}_{\mathrm{RC}}: 30.13 \%, \mathrm{Cl}_{\mathrm{M}}: 30.11 \%, \mathrm{Cl}_{\mathrm{CVX}}$ : $20.38 \%$. The models for other credibility indices have adjusted $\mathrm{R}^{2}$ values lower than \%10. In addition to having the highest explanatory power, the model for $\mathrm{Cl}_{\mathrm{CK}}$ has the lowest Akaike and Schwarz information criteria values (1.5521 and 1.6874, respectively) among all models. Thus, we can say that $\mathrm{Cl}_{\mathrm{CK}}$ is the best credibility index in explaining the variations in policy rate.

\footnotetext{
${ }^{4}$ Statistical tests for heteroskedasticity, serial correlation, model misspecification and structural break are given in the Appendix.

${ }^{5}$ In order to overcome the serial correlation and heteroskedasticity in the error terms, Newey-West standard errors are used to compensate the serial correlation and heteroskedasticity.
} 
Table 5. Estimation of $D\left(i_{C B}\right)$

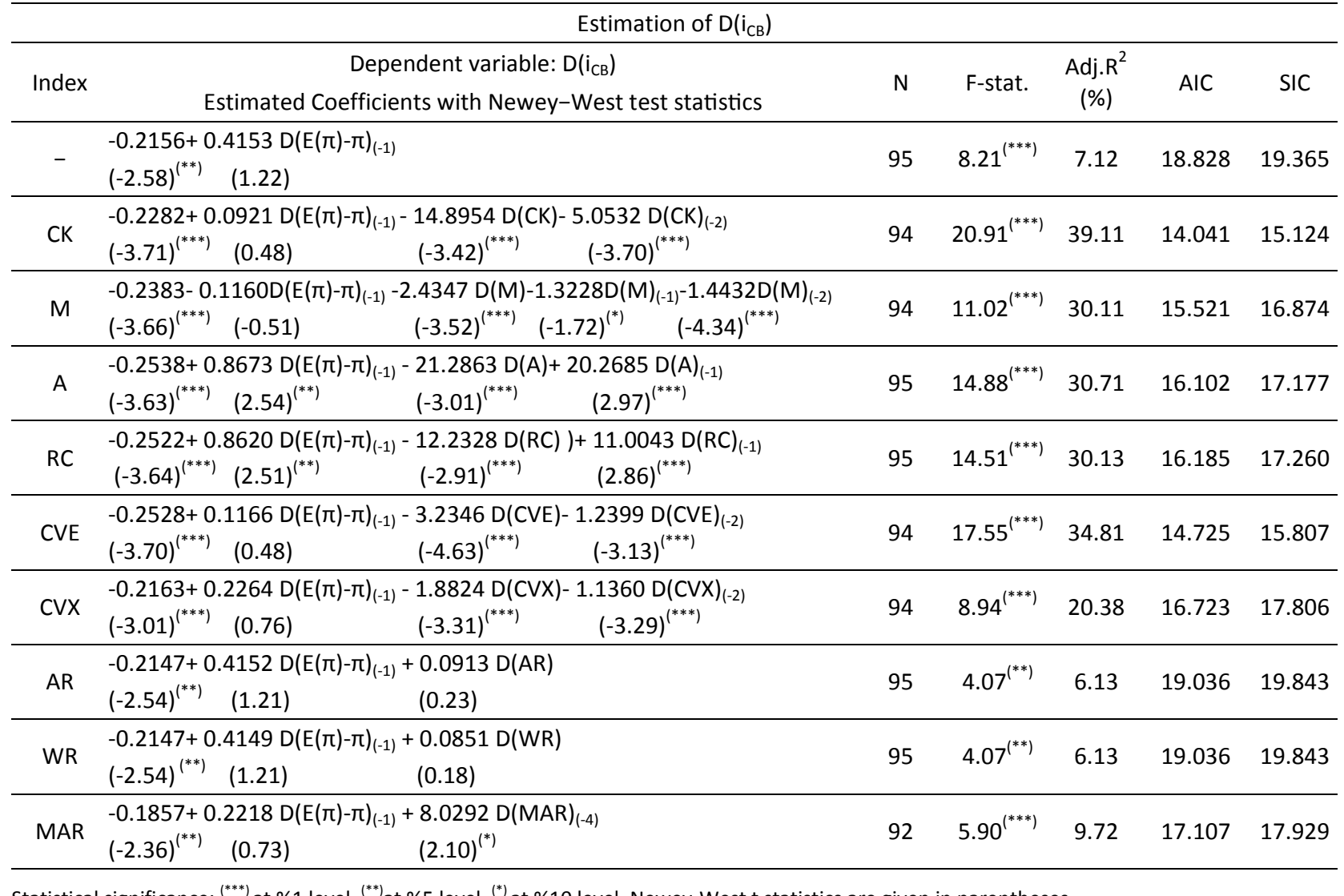

Statistical significance: ${ }^{(* *)}$ at $\% 1$ level, ${ }^{\left({ }^{* *}\right)}$ at $\% 5$ level, ${ }^{(*)}$ at $\% 10$ level. Newey-West t statistics are given in parentheses. 
Table 6. Estimation of $\mathrm{D}\left(\mathrm{i}_{\mathrm{MAR}}\right)$

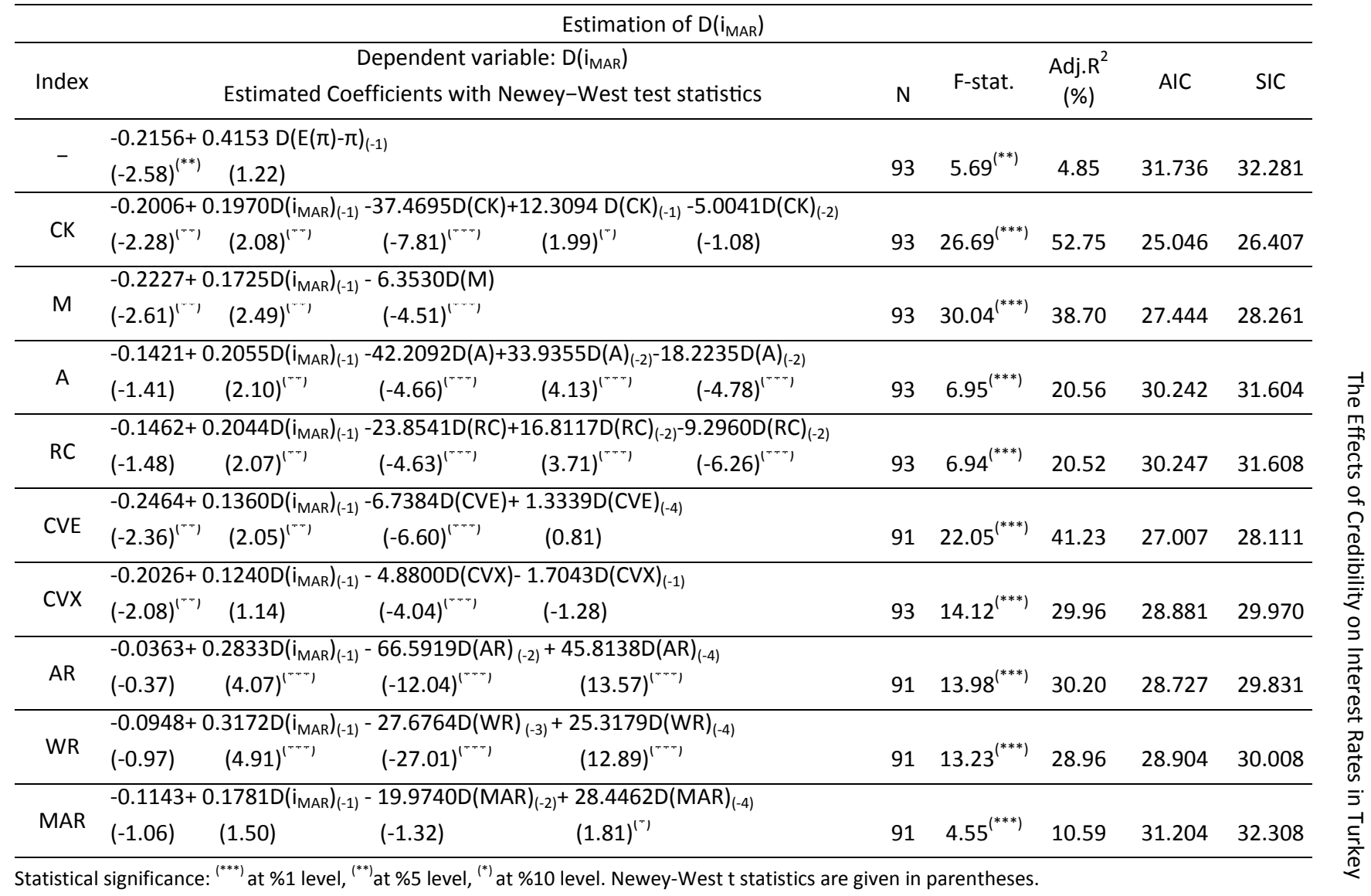


Note that the credibility indices based on reputation $\left(\mathrm{Cl}_{A R}, \mathrm{Cl}_{\mathrm{WR}}, \mathrm{Cl}_{\mathrm{MAR}}\right)$ has no power in explaining the $D\left(i_{C B}\right)$. These credibility indices have positive coefficients contrary to our expectation. Moreover, the adjusted $\mathrm{R}^{2}$ values of the models of $\mathrm{Cl}_{\mathrm{AR}}$ and $\mathrm{Cl}_{\mathrm{WR}}$ are even lower than the model with pure control variable $\left.(E(\pi)-\pi)_{(-1)}\right)$.

The second model (eq. 2) explains the variations in market interest rate by using the changes in credibility indices. The variation in market interest rate in the previous period is included in the model as control variable. If the variations in market interest rates move inversely with changes in credibility, then an increase in a credibility index should reduce the variations in market interest rates.

We therefore expect negative and statistical significance coefficients for credibility indices in the estimation of the second model.

We select the appropriate model by using Akaike and Schwarz information criteria for each credibility index. Estimation results for the variations in policy rate are shown in Table $6 .^{6}$

In the estimation of the variation in market interest rate, all of the models with credibility indices are statistically significant at \%1 level. By comparing the models in terms of adjusted $\mathrm{R}^{2}$, it is seen that the best credibility index is $\mathrm{Cl}_{\mathrm{CK}}$ which explains the $52.75 \%$ of the variation in the $D\left(i_{M A R}\right)$. Note that only $\% 4.85$ of the variation in $\mathrm{D}\left(\mathrm{IR}_{\mathrm{M}}\right)$ is explained by control variable (lag of itself). Following $\mathrm{Cl}_{\mathrm{CK}}$, the highest adjusted $\mathrm{R}^{2}$ values are as follows. $\mathrm{Cl}_{\mathrm{CVE}}: 41.23 \%, \mathrm{Cl}_{\mathrm{M}}: 38.70 \%, \mathrm{Cl}_{\mathrm{AR}}: 30.20 \%$, $\mathrm{Cl}_{\mathrm{CVX}}: 29.96 \%, \mathrm{Cl}_{\mathrm{WR}}: 28.96 \%$. Other credibility indices have adjusted $\mathrm{R}^{2}$ values lower than $\% 21$.

In addition to having the highest explanatory power, the model for $\mathrm{Cl}_{\mathrm{CK}}$ has the lowest Akaike and Schwarz information criteria values (2.5046 and 2.6407, respectively) among all models. Thus, we can say that $\mathrm{Cl}_{\mathrm{CK}}$ is the best credibility index in explaining the variations in market interest rate.

\section{Conclusion}

Credibility of the monetary authority is a crucial indicator that can promise the consistency of the policy decision. It decreases the cost of disinflation under inflation targeting regimes. The measurement of credibility is therefore important for the analysis of countries adopting inflation targeting. This study evaluates nine credibility indices to measure the credibility of central bank of Turkey between January 2004 and January 2012. Six of these indices are based on the deviation of inflation expectation from the inflation target and the rest are based on the reputation (past performance) of the central bank.

\footnotetext{
${ }^{6}$ Newey-West standard errors are used in estimation. Thus results will be robust to serial correlation and heteroskedasticity.
} 
We provide empirical evidence supporting the claim that higher credibility will lead to lower variations in interest rates of both monetary policy and the market. Moreover, we showed that $\mathrm{Cl}_{\mathrm{CK}}$ (proposed by Cecchetti and Krause, 2002) is the best credibility index in explaining the variations both in policy rate and market interest rate in Turkish case.

\section{References}

Agénor, P. \& Taylor, M.P. (1993) "Analysing credibility in high-inflation countries: a new approach." Economic Journal 103: 329-36.

http://dx.doi.org/10.2307/2234771

Barro R.B. \& Gordon, D.B. (1983) "Rules, Discretion, and Reputation in a Model of Monetary Policy." Journal of Monetary Economics 12: 101-20.

http://dx.doi.org/10.1016/0304-3932(83)90051-X

Cecchetti, S.G. \& Krause, S. (2002) "Central bank structure, policy efficiency and macroeconomic performance: exploring empirical relationships." Federal Reserve Bank of St. Louis Review July/August: 47-60.

de Mendonça, H.F. (2004) "Mensurando a Credibilidade do Regime de Metas Inflacionárias no Brasil." Revista de Economia Política 24: 344-50.

de Mendonça, H.F. (2007) "Towards credibility from inflation targeting: the Brazilian experience." Applied Economics 39: 2599-615. http://dx.doi.org/10.1080/00036840600707324

de Mendonça, H.F. \& Souza, G.J. (2009) "Inflation targeting credibility and reputation: The consequences for the interest rate." Economic Modelling 26: 1228-38. http://dx.doi.org/10.1016/j.econmod.2009.05.010

Faust J. \& Svensson L.E.O. (2001) "Transparency and Credibility: Monetary Policy With Unobservable Goals." International Economic Review 42: 369-97. http://dx.doi.org/10.1111/1468-2354.00114

Kara, H. \& Kucuk-Tuğer, H. (2010) "Inflation expectations in Turkey: learning to be rational." Applied Economics 42: 2725-42.

http://dx.doi.org/10.1080/00036840801964559

Kydland, F.E. \& Prescott, E.C. (1977) "Rules Rather Than Discretion: The Inconsistency of Optimal Plans." Journal of Political Economy 85: 473-92.

http://dx.doi.org/10.1086/260580

Mackiewicz-Lyziak, J. (2009) "Central bank credibility: determinants and measurement. A cross-country study", SMYE Spring Meeting, Istanbul, Turkey.

Nahon, B. F. \& Meuer, R. (2009) “Measuring Brazilian Central Bank Credibility Under Inflation Targeting." International Research Journal of Finance and Economics 27: 72-81.

Sicsú, J. (2002) "Expectativas Inflacionárias no Regime de Metas de Inflação: uma análise preliminar do caso brasileiro." Economia Aplicada 6: 703-11.

Svensson, L.E.O. (2000) "How should monetary policy be conducted in an era of price stability?" NBER Working Paper 7516. 
M. Kadir DOGAN \& Gulcan BOZDEMIR

\section{Appendix: Statistical Tests for the Models.}

Statistical tests for Models Explaining the Variations in Policy Rate

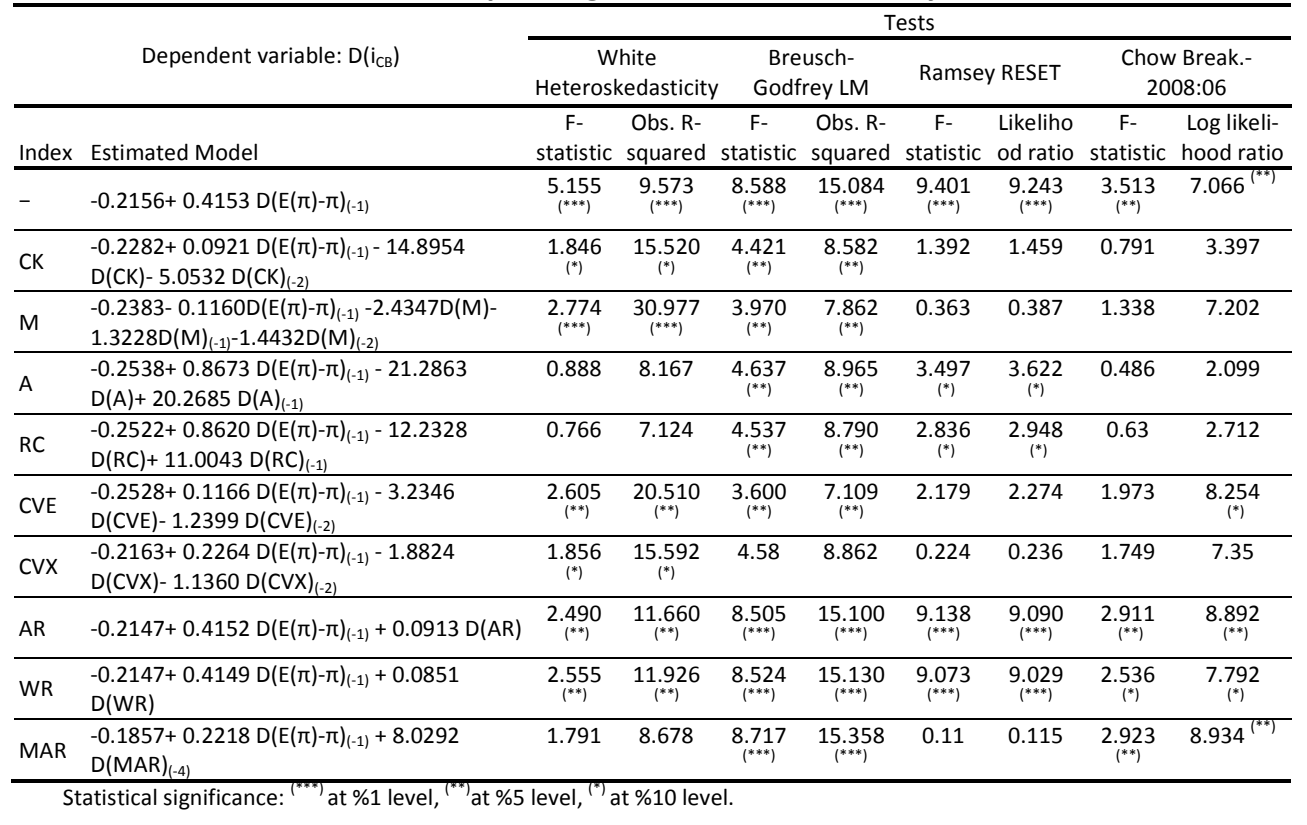

Statistical Tests for Models Explaining the Variations in Market Interest Rate

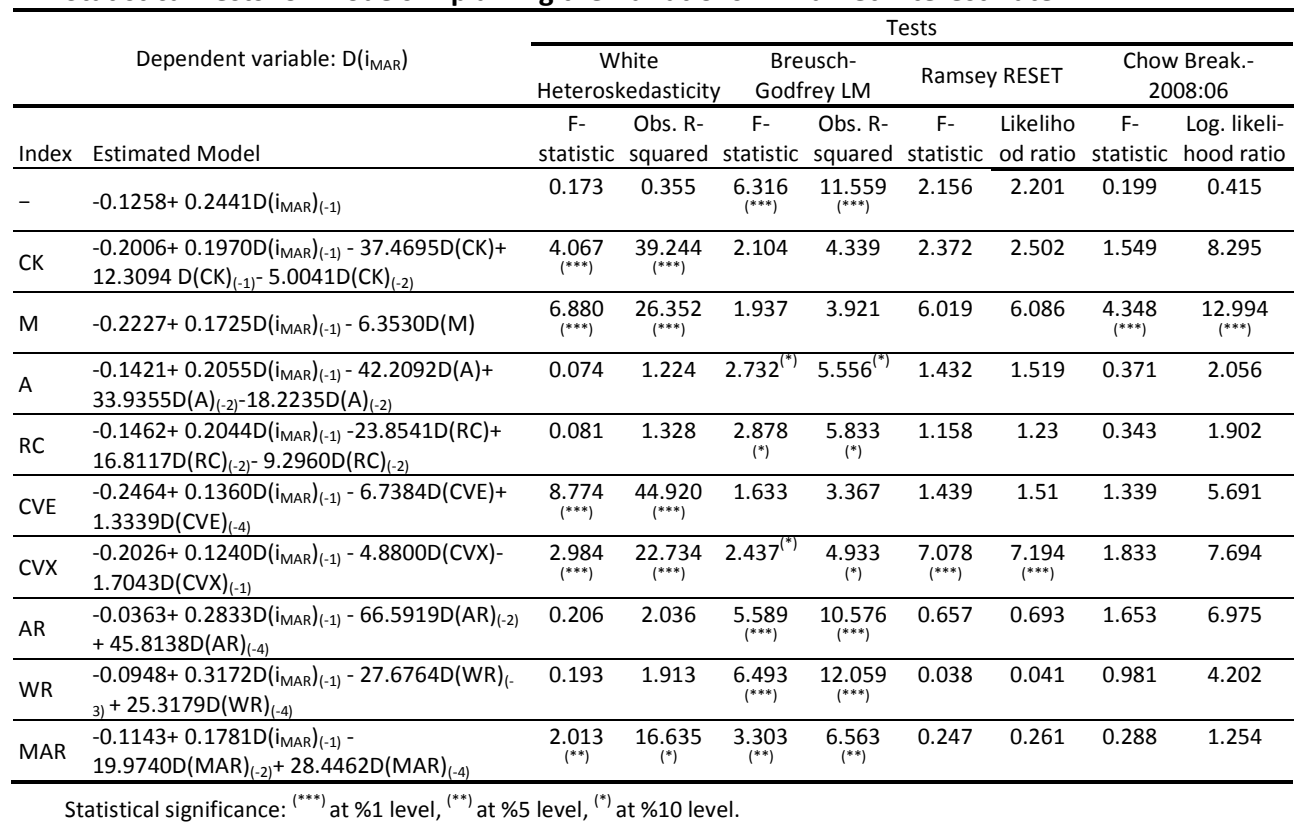

